\title{
Evaluation of a Water System Model for Educational Research
}

\author{
Sarah Meidl Zahorodny¹, Dennis Webb², Marcia R. Silva ${ }^{1 *}$ \\ ${ }^{1}$ Water Technology Accelerator (WaTA), University of Wisconsin-Milwaukee, Milwaukee, WI, USA \\ ${ }^{2}$ Sage Water LLC, Milwaukee, WI, USA \\ Email:msilva@uwm.edu
}

How to cite this paper: Zahorodny, S. M., Webb, D., \& Silva, M. R. (2022). Evaluation of a Water System Model for Educational Research. Creative Education, 13, 637-657. https://doi.org/10.4236/ce.2022.132040

Received: January 14, 2022

Accepted: February 20, 2022

Published: February 23, 2022

Copyright (C) 2022 by author(s) and Scientific Research Publishing Inc. This work is licensed under the Creative Commons Attribution International License (CC BY 4.0).

http://creativecommons.org/licenses/by/4.0/

\begin{abstract}
The water industry has been facing a lack of young, qualified workers for many years while simultaneously having aging employees retire or change fields. This is creating a lack of workers in treatment plants. As technology has become more advanced, the industry has also become more automated. This should make it easier in the future to attract and train young people to the sector due to their interest in automation and computer learning. The creation and adaption of didactic computer simulators and virtual reality programs is one method the water industry has begun using in training to try to attract young workers. We use Festo's Environmental Discovery System ${ }^{\circledR}$ (EDS) for Water Management to prove the usefulness of these systems.
\end{abstract}

\section{Keywords}

Environmental Discovery System (EDS), Educational Research, Flocculation, Water Treatment, Water System Model

\section{Introduction}

Water and wastewater treatment plants are facing the crisis of an aging workforce. According to a report by the Brookings Institute, the number of retirements in the water sector workforce is leading to staffing vacancies of up to $50 \%$. The average age of workers in the water industry is 42.8 years, which is slightly older than the national median across all jobs, which is 42.2 years. However, some areas of the water sector have skilled workers that are significantly older than the national average, such as water treatment plant operators, who have an average age of 46.4 years. The U.S. Bureau of Labor Statistics (BLS) also estimates that each year from 2016 to 2026, about $10.6 \%$ of workers in the water sector will either retire or transfer out of the field (Kane \& Tomer, 2018). The 
BLS estimates that during this time, there will be 9200 job openings each year in the United States water sector (Kane \& Tomer, 2018; United States Government Accountability Office, 2018). An aging workforce was listed as the eighth out of 30 most pressing issues facing water utilities in 2019 (Flancher, 2019). Beyond simply having an aging workforce, the water industry has a lack of young workers. Only $10.2 \%$ of workers were between the ages of 22 and 24 in 2018 (Kane \& Tomer, 2018). Other countries are facing the same dilemma. In Australia in 2016, about a third of the water sector workforce was over the age of 51 (Gralton, 2018). Similarly, in the United States in 2016, 24.7\% of water operators were 55 years of age or older (United States Government Accountability Office, 2018). Both the aging workforce and the lack of young workers in the water industry make training new talent extremely important. One challenge with training is that water treatment plants are becoming more automated. Because of this, operators are becoming supervisors that monitor the plant rather than continually controlling it. This lack of continuous control means that operators no longer receive as much on the job training leading them to have more trouble dealing with disruptions in operation (Van der Wees, 2009; Worm et al., 2012).

Many product manufacturers are trying to address the difficulties of training and attracting young people by creating computer simulators and virtual reality programs of water and wastewater treatment. One of the hopes is that by doing this, it will make training more appealing to young people by making it more game-like. It is also thought that computer-based training may help improve the technological skills of trainees, which is necessary due to the increasing automation of treatment plants (Lui et al., 2012; Mirauda et al., 2019).

Waterspot is a drinking water simulator developed for the Weesperkarspel drinking water treatment plant in Amsterdam. One of the reasons this simulator was developed was to try to fill the skill gap of operators created by increasing plant automation (Van der Wees, 2009). The Waterspot Simulator allows for both operator training and process optimization (Lapikas et al., 2009; Van Der Helm et al., 2012). The virtual treatment plant can be either manually controlled or partially automated. Changing a pump speed, valve position, or chemical dosage shows their effect on the division of flows in the treatment plant and/or on the chemical properties of the water (Worm et al., 2012). The simulator allows for modelling ozonation, pellet softening, and activated carbon filtration processes. Waterspot uses real-time and historical data of on-line water quality measurements, flow measurements, process data, and water quality laboratory measurements in the simulator. This helps to provide more realistic training for operators. The virtual plant is also run using a SCADA (supervisory control and data acquisition) interface, which helps improve the reality of training. Despite the possibilities of using Waterspot for training operators, the plant decided not to begin training operators and instead is doing further research on the simulator (Van Der Helm et al., 2012).

Another platform that has been used for training is LabVIEW. LabVIEW is a 
3D modeling software. It has been used in university programs to create virtual labs to teach hydraulic pump diagnostics and flow meter calibration, as well as to track the profile of the jet trajectory from an orifice fitted in a tank and to draw the flow net for a given velocity potential stream function (Mirauda et al., 2019; Nedeljkovic et al., 2019).

The Wastewater Treatment Simulation (WaTr Sim) is a computer-based simulation of a plant for purifying wastewater. The focus of the operator is to have as little wastewater remaining at the end of the simulation as possible. There are four different processes that an operator handles in WaTr Sim to achieve this purpose. These processes are: 1) delivery, during which tank trucks bring wastewater to the plant; 2) homogenization, where wastewater is mixed to a 50:50 ratio of water and solvents and brought to an even temperature; 3) separation, during which the operator separates the water and solvents by bring the mixture to a boil in a distillation column; 4) and finally, product repository, where products and waste are received and moved on for further processing. The simulation also logs the interactions between the operator and simulation. This can then be viewed after using the simulation and allows performance to be evaluated. The simulator also includes five alternate scenarios to increase the operators' experience. There is a start-up and a shut-down scenario as well as two scenarios affecting truck delivery and one including heavy rainfall. Each of these scenarios changes how the operator must run the plant and provides experience beyond the default settings. WaTr Sim can also be altered, and new features can be added to tailor the simulation to the needs of the user. Research has suggested that this simulator can be used in training experiments to analyze the demands of process control tasks. Unfortunately, WaTr Sim is only available for experimental use and is not for sale. Furthermore, the user manual is only available in German, which limits the number of people who can use the simulator (Burkolter et al., 2009). After the date of this referenced paper, further information does not appear to be available.

StreamflowVL is a virtual laboratory that was designed for Hydraulics Engineering students at the University of Basilicata in Italy to be used in combination with traditional teaching methods. This virtual laboratory was designed to help students familiarize themselves with sophisticated equipment and advanced methodologies for the measurement of the water discharge in open-channel flows (Mirauda et al., 2019). Treatment plants such as the Milwaukee Metropolitan Sewerage District (MMSD), often sample water from surrounding rivers and lakes to test for new sources of pollution and may find such training useful (MMSD, n.d.). This simulation differs from many others because it does not focus on working in a treatment plant, but rather on collecting water samples from bodies of water. Traditionally, this must be practiced by going to rivers and collecting samples many times to learn proper methods and equipment handling. Learning to move within a river is also important. It can be difficult for students to get enough practice sample collection, especially in autumn and winter when 
there are poor weather conditions. There is also limited time during open-air exercises, making it challenging to complete an entire measurement procedure. The simulator makes it possible for students to complete the entire process, rather than just part of it, giving them a better idea of procedures. One challenge with this simulator is that manual skills are not improved through its use. The simulator also does not require the same amount of care as working in the field requires. This means that StreamflowVL should not replace traditional water sampling training but could be used to supplement it, instead (Mirauda et al., 2019, 2020).

EON Reality and Festo Didactic worked together to create a virtual reality simulation of a water treatment plant. The simulation allows users to virtually interact with the plant, machinery, and practice for emergency situations. Some of the operations included in the simulator are cleaning and reinstalling the water inlet sensor, operating bypass sliders, lifting the sand pump with a crane, and figuring out the best way to fix an oxygen probe. Users are also able to look over the entire treatment facility from a simulated control room (EON Reality, 2015). Furthermore, the system allows for practice with situations such as power failures, breakdowns, and accidents that can't be trained for in real-life (Festo Corporation, n.d.-a). This simulator allows students to make and learn from mistakes without real life, and sometimes dangerous, consequences. The simulator also brings together aspects of mechanics, electrics, chemistry, and biology, all of which are needed as a water or wastewater treatment professional. This helps provide a well-rounded experience for users (EON Reality, n.d.).

Festo Didactic, by itself, has also created educational material for water management, distribution, and treatment. One such product is the Environmental Discovery System ${ }^{\circledR}$ (EDS) for Water Management. This system includes both a computer program and a physical model of the water treatment process. The model includes four stations, the Water Purification station, the Water Supply station, the Wastewater Transport station, and the Wastewater Treatment station. These stations can be used individually or together to show how changing one station can affect the rest. The system includes handbooks with background information on different processes of treatment plants as well as exercises that can be carried out using the system (Festo Corporation, n.d.-b). To date, to the best of our knowledge, there are no research papers on the use of efficacy of the EDS $^{\circledR}$ for Water Management.

In this paper, we will focus on water and wastewater treatment plants that use coagulation and flocculation to remove suspended particles from water as one of the middle steps in drinking water purification. There are three steps to removing suspended particles from water. The first step is coagulation. A coagulant with positive charge is added which brings together negatively charged suspended particles and forms microflocs (Groß et al., 2013). The second step is flocculation. Flocculation occurs with gentle mixing which causes the microflocs to collide and form larger macroflocs (Prakash et al., 2014). Sedimentation is the third 
step for removing suspended solids. This is the step in which floc settles and can be removed. Multiple factors can affect the coagulant needed such as the type of particle load (organic, inorganic, or biological), temperature of the water, and the $\mathrm{pH}$ level of the water (Groß et al., 2013). Simple hydrolyzing metal salt (HMS) coagulants are aluminum sulfate $\left(\mathrm{Al}_{2}(\mathrm{SO} 4)_{3} \cdot 14 \mathrm{H}_{2} \mathrm{O}\right)$, also known as alum, ferric sulfate $\left(\mathrm{Fe}_{2}\left(\mathrm{SO}_{4}\right) 3 \cdot \mathrm{XH}_{2} \mathrm{O}\right)$, and ferric chloride $\left(\mathrm{FeCl}_{3} \cdot \mathrm{XH}_{2} \mathrm{O}\right)$ (American Water Works Association \& Edzwald, 2011). Generally, a multichamber system is utilized for this process. In the flash mix chamber, chemicals are added and mixed into the raw water. Significant turbulence is required here to ensure collision of the chemical and raw water particles. Water is then pumped into a flocculation chamber with lighter mixing so as not to disturb the formation of floc. The final chamber is the sedimentation chamber. Here, floc is allowed to settle to the bottom of the chamber while the clean water is permitted to flow from the top of the chamber into the rest of the treatment system. For this process to be done in a single chamber, different zones within the tank serve separate functions (Groß et al., 2013).

This paper looks at an iron flocculation experiment done using Festo's EDS ${ }^{\circledR}$ Water Management System as a model experiment, where synthetic raw water was created by adding sodium hydroxide to tap water and ferric chloride was used as a coagulant. This system demonstrates the process using a single chamber. Our goal is to evaluate whether the EDS system is a valuable tool to prepare students with hands-on experiments at pilot scale, bridging the gap between lab bench experiments and large-scale plants, and suggest improvements to the operation of the system to merge that gap and facilitate the process of preparing the next generation of workers in treatment plants.

\section{Materials and Methods}

\subsection{Materials}

Sodium hydroxide (50\%) solution (CAS \#1310-73-2) was used, which was obtained from Wheaton Scientific and from Cole-Parmer. A ferric chloride (100\%) solution (CAS \# 10025-77-1) was obtained from Ricca Chemical Company. The ferric chloride was diluted to two $40 \%$ solutions. Originally, 1 liter was made using $400 \mathrm{~mL}$ of ferric chloride and $600 \mathrm{~mL}$ of deionized water. An additional 200 $\mathrm{mL}$ of $40 \%$ solution was made using $120 \mathrm{~mL}$ of ferric chloride and $180 \mathrm{~mL}$ of deionized water.

\subsection{System Set-Up}

The iron flocculation experiment was done using the Water Purification and Water Supply stations of the Festo EDS $^{\circledR}$ for Water Management. The system was set up based on instructions obtained elsewhere (Groß et al., 2013). The closed loop of the water purification system (Figure 1) was expanded to connect the two stations according to the Piping \& Instrumentation Diagram (Figure 2). To run the system, the EasyPort ${ }^{\text {ti }}$ programmable controllers of both the Water 


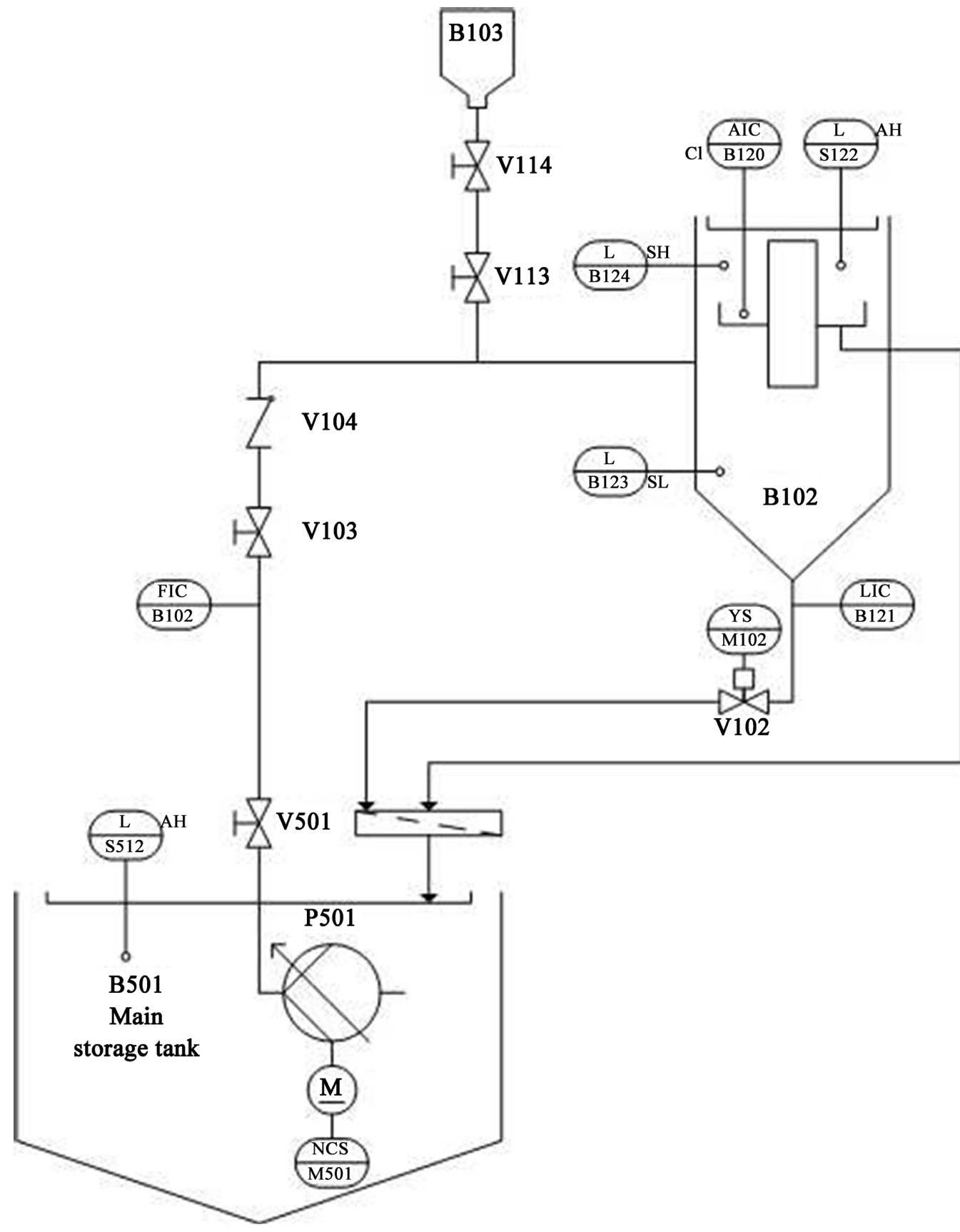

Figure 1. The piping and instrumentation diagram for the Water Purification system of the EDS $^{\circledR}$ for Water Management (Reproduced with permission of Tony Oran, FESTO USA).

Purification and Water Supply station were turned on. Then, the software, "FluidLab Water Management" (FESTO, version.07 by ADIRON Copyright 2012) was started on the connected PC. The "Initialize" button was pressed for both stations and then the picture for the stations was clicked on to open their control panels.

\subsection{Methodology}

This experiment was based on instructions obtained elsewhere (Groß et al., 2013). 


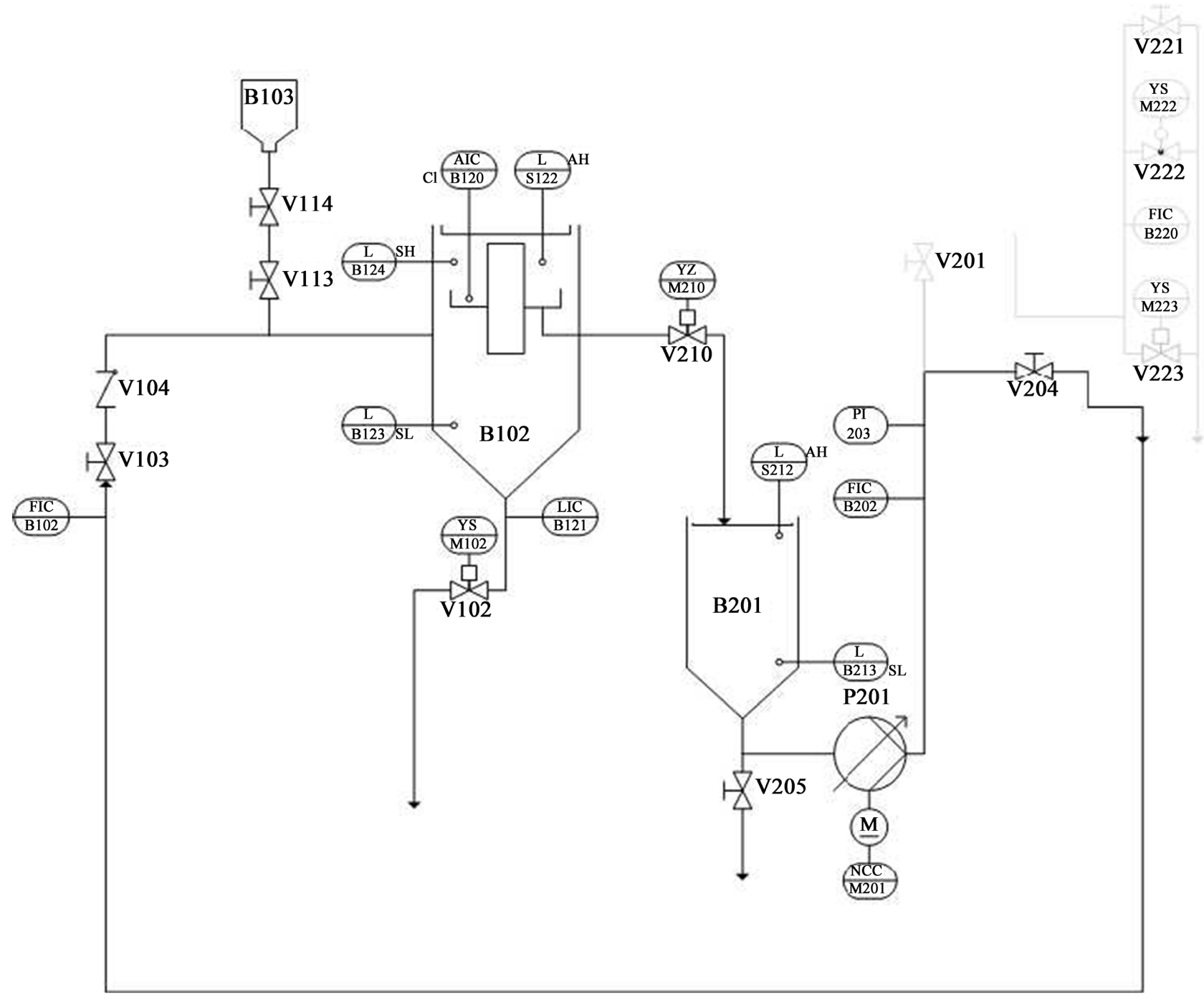

Figure 2. The piping and instrumentation diagram for the experiment ((Reproduced with permission of Tony Oran, FESTO USA).

However, the instructions only call for doing one run using $32 \mathrm{~mL}$ sodium hydroxide (50\%) and $54 \mathrm{~mL}$ ferric chloride (40\%). Variations using $15 \mathrm{~mL}$ sodium hydroxide $(50 \%)$ and $54 \mathrm{~mL}$ ferric chloride $(40 \%), 50 \mathrm{~mL}$ sodium hydroxide (50\%) and $54 \mathrm{~mL}$ ferric chloride (40\%), $32 \mathrm{~mL}$ sodium hydroxide (50\%) and 25 $\mathrm{mL}$ ferric chloride (40\%) were also used. A fifth variation, $32 \mathrm{~mL}$ sodium hydroxide (50\%) and $75 \mathrm{~mL}$ ferric chloride (40\%), was planned, but could not be completed due to time constraints and lack of an adequate supply of ferric chloride. Three runs of each variation were done except for the $32 \mathrm{~mL}$ sodium hydroxide (50\%) and $54 \mathrm{~mL}$ ferric chloride (40\%) variation. This variation had six runs. The first three runs were used to figure out timing for the sampling and did not have standardized timing for sample draws. To enhance our understanding of the experiment we kept samples of each solution prepared and took additional measurements of the solutions. This included taking measurements of $\mathrm{pH}$ and conductivity.

We used ferric chloride as our HMS to coagulate our raw water solution. 
When ferric chloride is added in sufficient concentrations, it reacts with hydroxides $(\mathrm{OH}-)$ to form solid ferric oxyhydroxide, floc $\left(\mathrm{FeOH}_{3}\right)$. Suspended particles are trapped in the precipitate and can be removed from the water along with the floc (Shammas, 2005). Ferric chloride can be used to remove organic materials, some viruses, arsenic, and algae (Bratby, 2016; Samrani et al., 2004). In this paper, the ferric chloride and sodium hydroxide combined to form sodium chloride and ferric oxyhydroxide according to the formula:

$$
\mathrm{FeCl}_{3}+3 \mathrm{NaOH} \rightarrow 3 \mathrm{NaCl}+\mathrm{Fe}(\mathrm{OH})_{3}(\mathrm{~s}) \downarrow
$$

The ferric oxyhydroxide is a solid and forms a precipitate at the bottom of the tank.

As noted previously, Festo's system demonstrates the coagulation and flocculation process in a single tank, rather than a multichamber system. The "raw water" is held in tank B201. Tank B102 acts as the mixing, flocculation, and sedimentation chamber all in one. The middle of B102 works as the mixing chamber. The flow of water from B201 into B102 provides the turbulence required to mix the coagulant with the raw water. The lower part of B102 (B102L) works as the flocculation and sedimentation chambers. Provided the water from B201 is not flowing too quickly, the floc is able to form and settle with only minor disturbance here. Once the water rises sufficiently, the weir at the upper part of B102 (B102U) then allows the cleaned water to overflow back into B201 which now symbolizes the next steps in the treatment process.

\subsubsection{Optimization and Standardization of EDS ${ }^{\circledR}$ Parameters}

Several test runs were done without collecting samples to be sure the experiment was running properly. Initially, the instructions in the workbook were misread and too little sodium hydroxide was added. When no flocculation occurred, small amounts of sodium hydroxide were added. Eventually, flocculation did begin. This led to a reread of the instructions and the correct amount of sodium hydroxide was found, which was significantly higher than the original amount used. The water flow into tank B102 was also experimented with. Because the flow meter was not working properly, pump P201 could not be set to a specific flow rate. Instead, valve V210 was partially closed to control the flow. When the valve was open all the way, tank B201 filled too fast and did not allow for gentle mixing and enough time for the sodium hydroxide and ferric chloride to react so that the floc would form and settle. Closing valve V210 about $45^{\circ}$ slowed the flow sufficiently. The instructions in the workbook said to set the delivery rate of the ferric chloride to about 5 drops per second using valve V113. However, only opening this valve enough to allow drops into tank B102 could not achieve this rate and was too slow. Tank B102 would fill too far before all the ferric chloride entered the tank and the same problem that occurred with an excessive water flow rate resulted. Instead, valve V113 was opened completely, and the ferric chloride was allowed out in a steady stream.

Before adding water to the system, valve V205 was closed. Tank B201 was 
filled with $1.5 \mathrm{~L}$ of tap water by pouring the water into the top of the tank. Pump P201 was started by turning on Switch 3 at the bottom of the Water Supply control panel on the EDS $^{\circledR}$ software graphic user interface (GUI). The pump was run until water filled the piping to tank B102 and the piping was clear of large air bubbles. If bubbles continued to exit the pump, it was turned on and off until bubbles were no longer released. Water is approximately 1000 times denser than air so the pump will not work properly if it has air stuck in inside. If needed, more water was added until this could be accomplished. Any water collected in tank B102 was drained into a waste bucket by clicking software Switch 1 at the bottom of the Water Purification control panel to open valve V102. Then the valve was closed by clicking the switch again which activates a solenoid to reposition the valve.

Tank B201 was then filled to the $2 \mathrm{~L}$ mark with tap water. The proper amount of sodium hydroxide was added and then the tank was filled to $3 \mathrm{~L}$ mark with tap water. Valve V210 was partially closed by turning it about $45^{\circ}$. The valve was also marked to make it easy to turn the valve to the same location for each run. Tank B103 was filled with the proper amount of ferric chloride (40\%) with its valve, V114, closed. Valve V113 was opened completely. To begin the run, pump P201 was turned on and a timer was started. As soon as the pump was started, the ferric chloride was allowed to drain into the water by opening valve V114 completely.

A $25 \mathrm{~mL}$ graduated pipet was used to draw $20 \mathrm{~mL}$ samples that were collected in Falcon $50 \mathrm{~mL}$ polypropylene conical tubes. Vials were labelled with the amounts of sodium hydroxide and ferric chloride used in the run, the run number, the time taken and the location of the draw. Each run resulted in a total of 10 samples. Each time a sample was drawn, the time it was taken was written in a table. A total of four sets of samples were taken per run. A sample was drawn from tank B201 after it was filled with sodium hydroxide and water but before running the experiment. Samples were also drawn from the very top of the water in tank B102 just outside of the weir, from the middle of the floc formed at the bottom of tank B102, and from tank B201. The samples were drawn when the water in tank B102 reached the top of the weir and began to overflow into tank B201. The next set of samples was taken 2 minutes after the final sample from the previous set was drawn. After the system had run for 10 minutes, pump P201 was turned off by clicking Switch 3 in the Water Supply control panel. The floc was permitted to settle for two minutes before the final samples were taken. A sample of tap water was also collected for comparison.

After the final sample was taken, tanks B102 and B201 were drained into the waste bucket by opening valves V102 and V205. The valves were closed, and the system was run with plain tap water to rinse it out. All the tap water was drained, and the system was set for the next run.

After several runs, it appeared that backflow valve V104 failed. Since tank B102 is higher than B201, this valve is meant to prevent water from flowing 
backwards from B102 to B201 through the piping that brings water from B201 to B102 when the pump is not running. To prevent backflow during the settling period when the pump was turned off, valve V103 was closed as soon as pump P201 was stopped. This had to be done for runs two and three of the $32-\mathrm{mL}$ sodium hydroxide $(50 \%)$ and $25 \mathrm{~mL}$ ferric chloride (40\%) variation and all three runs of the $32 \mathrm{~mL}$ sodium hydroxide $(50 \%)$ and $54 \mathrm{~mL}$ ferric chloride (40\%) variation.

\subsection{Characterization of Water Samples}

\subsection{1. pH Testing}

The $\mathrm{pH}$ testing was done using the Oakton PCTS 50 handheld $\mathrm{pH}$ meter. Before testing, the meter was calibrated with $\mathrm{pH} 4,7$, and 10 standards. Each sample was shaken and then poured into the cap of the meter to the "Max" fill line. The meter was attached to the cap, and it was checked that there were no air bubbles around the electrode. The meter reading was allowed to stabilize until a check mark appeared. The resulting $\mathrm{pH}$ was written in a table. The cap and electrode were rinsed with deionized water between each sample.

\subsubsection{Turbidity Testing}

Turbidity testing was done using a La Motte 2020 we Turbidimeter. Prior to testing, the turbidity meter was calibrated using 20 and 200 NTU standards. Each sample was shaken prior to testing. After shaking the sample, it was poured into the testing vial. The vial was wiped off with a Kim wipe and inserted into the turbidity meter. The reading was written in a table. After testing, the sample was returned to its sample vial. The testing vial was washed and dried between each sample.

\subsubsection{Conductivity Testing}

Conductivity testing was done using the YSI Model 32 Conductance Meter. The function knob was set to "Conductance" and the temperature coefficient was set to 2.7. To check that the meter was reading properly, Oakton Conductivity Standards of 84 and $1413 \mathrm{microohms} / \mathrm{cm}$ were measured. The cell constant used was $\mathrm{K}=1 / \mathrm{cm}$. Each sample was shaken and then the electrode was dipped in several times and stirred to be sure that no air was trapped in the electrode chamber before being held submerged in the sample. The range was set to the lowest value that resulted in a reading. Over-range values were indicated by a "1" and under-range values were indicated by a " $u$ ". Once the reading stabilized, the value and range used were written in a table. The electrode was rinsed between samples with deionized water and excess water was patted off with a Kim wipe.

\subsection{Data Analysis}

Graphs were created using SigmaPlot 14.0. The graphs compare the average $\mathrm{pH}$ and conductance of each sample location (Tank B102U, Tank B102L, and Tank B201) over time for each variation of sodium hydroxide and ferric chloride. 


\section{Discussion}

In this series of experiments, our goal was to demonstrate that a sophisticated training system can be used to educate technical students on drinking water purification processes. And that the results of chemistry variations in raw water and coagulant chemistry used for flocculation are controllable and measurable in a model system. Raw water was made with $\mathrm{NaOH}$ mixed with tap water, then the $\mathrm{FeCl}_{3}$ coagulant was added.

The following chemistry solution variations were used:

$15 \mathrm{ml} \mathrm{NaOH}$ (50\%), $54 \mathrm{ml} \mathrm{FeCl}_{3}$ (40\%)

$32 \mathrm{ml} \mathrm{NaOH}$ (50\%), $54 \mathrm{ml} 32 \mathrm{ml} \mathrm{NaOH}$ (50\%), $25 \mathrm{ml} \mathrm{FeCl}_{3}$ (40\%)

$\mathrm{FeCl}_{3}(40 \%)$

$50 \mathrm{ml} \mathrm{NaOH}$ (50\%), $54 \mathrm{ml} \mathrm{FeCl}_{3}$ (40\%)

We performed three runs of variations 1,2 , and 4 , and six runs of variation 3 using the methods explained in section 2 of this paper. Tank B201, was the tank holding raw water and tank B102 was the mixing tank used to dose the raw water with $\mathrm{FeCl}_{3}$ coagulant. Samples for evaluation were taken at various points in these tanks.

Raw water was transported from tank B201 to tank B102, and iron chloride was gradually added. Samples were taken from $U$, the upper portion of tank B102 just before the water ran over a weir for transport to tank B201 as purified water, and $\mathrm{L}$, the lower portion of tank B102 where precipitation of flocs occurred. The flocs created during the various experiment mixtures were of varying degrees of density. Figure 3 represents the visual affect created when the flocs began to develop.

This chemical reaction is as follows:

$$
\mathrm{FeCl}_{3}+3 \mathrm{NaOH}->3 \mathrm{NaCl}+\mathrm{Fe}(\mathrm{OH})_{3}(\mathrm{~s})
$$

The following is a summary of average results and patterns for $\mathrm{pH}$, conductance, and turbidity.

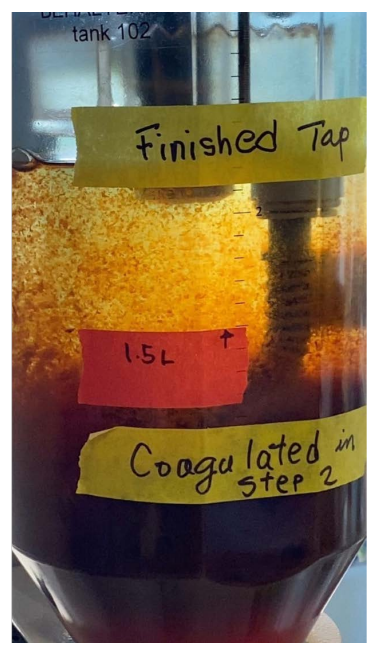

Figure 3. Tank B102 in the middle of flocculation. Floc is beginning to settle to the bottom of the tank as the water rises to the weir. 


\subsection{Acidity (pH)}

The $\mathrm{pH}$ of the various fluids remaining after cycling the experiments was measured with the following results:

Samples from tank location B102U resulted in similar $\mathrm{pH}$ results for all runs with only a variation from 12 to $12.5 \mathrm{pH}$ (Figure 4). Variation from highest $\mathrm{pH}$ to lowest $\mathrm{pH}$ was as follows for the performed experimental runs:

$15 \mathrm{~mL} \mathrm{NaOH}, 54 \mathrm{~mL} \mathrm{FeCl}_{3}$

$32 \mathrm{~mL} \mathrm{NaOH}, 54 \mathrm{~mL} \mathrm{FeCl}_{3}$, runs 4 - 6

$32 \mathrm{~mL} \mathrm{NaOH}, 25 \mathrm{~mL} \mathrm{FeCl}_{3}$

$32 \mathrm{~mL} \mathrm{NaOH}, 54 \mathrm{~mL} \mathrm{FeCl}_{3}$, runs 1 - 3

$50 \mathrm{~mL} \mathrm{NaOH}, 54 \mathrm{~mL} \mathrm{FeCl}_{3}$

Tank location B102L, however, had a broad range of acidity (Figure 5). Some of the samples resulted in heavy opaque floc (Figure 6, right), while others were a dark, transparent brown liquid with no floc (Figure 6, left). Why this happened is unsure. Samples with heavy opaque floc precipitant were very basic, and those that were the dark brown liquid were very acidic. Because of the variation, it is difficult to discern much of a consistent pattern. It does appear that variations $32 \mathrm{~mL} \mathrm{NaOH}, 25 \mathrm{~mL} \mathrm{FeCl}_{3}$ and $32 \mathrm{~mL} \mathrm{NaOH}, 54 \mathrm{~mL} \mathrm{FeCl}_{3}$ (runs 1 - 3 and runs $4-6$ ) all decrease in $\mathrm{pH}$ after the first two samplings. Variations $15 \mathrm{~mL}$

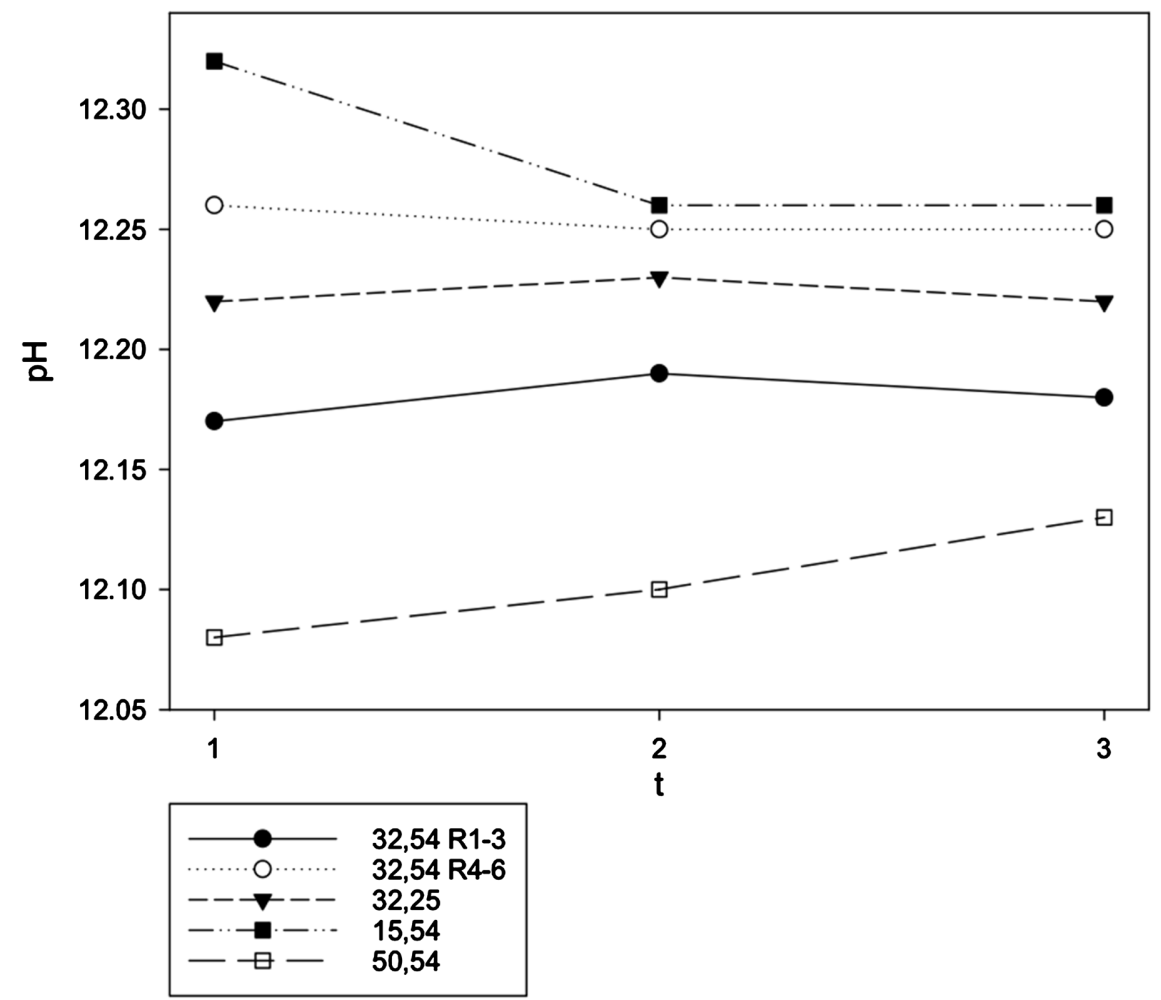

Figure 4. Tank B102U pH: average $\mathrm{pH}$ values of the samples taken from tank B102U throughout each run for each variation. $\mathrm{T}$ is the time of the draw. $\mathbf{1}$ is when water reached the weir in tank B102; 2 is 2 minutes after the first draw; 3 is after the 2 minutes settling period after the system ran for 10 minutes. In graph legend, the number of milliliters of $\mathrm{NaOH}$ is first, followed by $\mathrm{FeCl}_{3}$. 


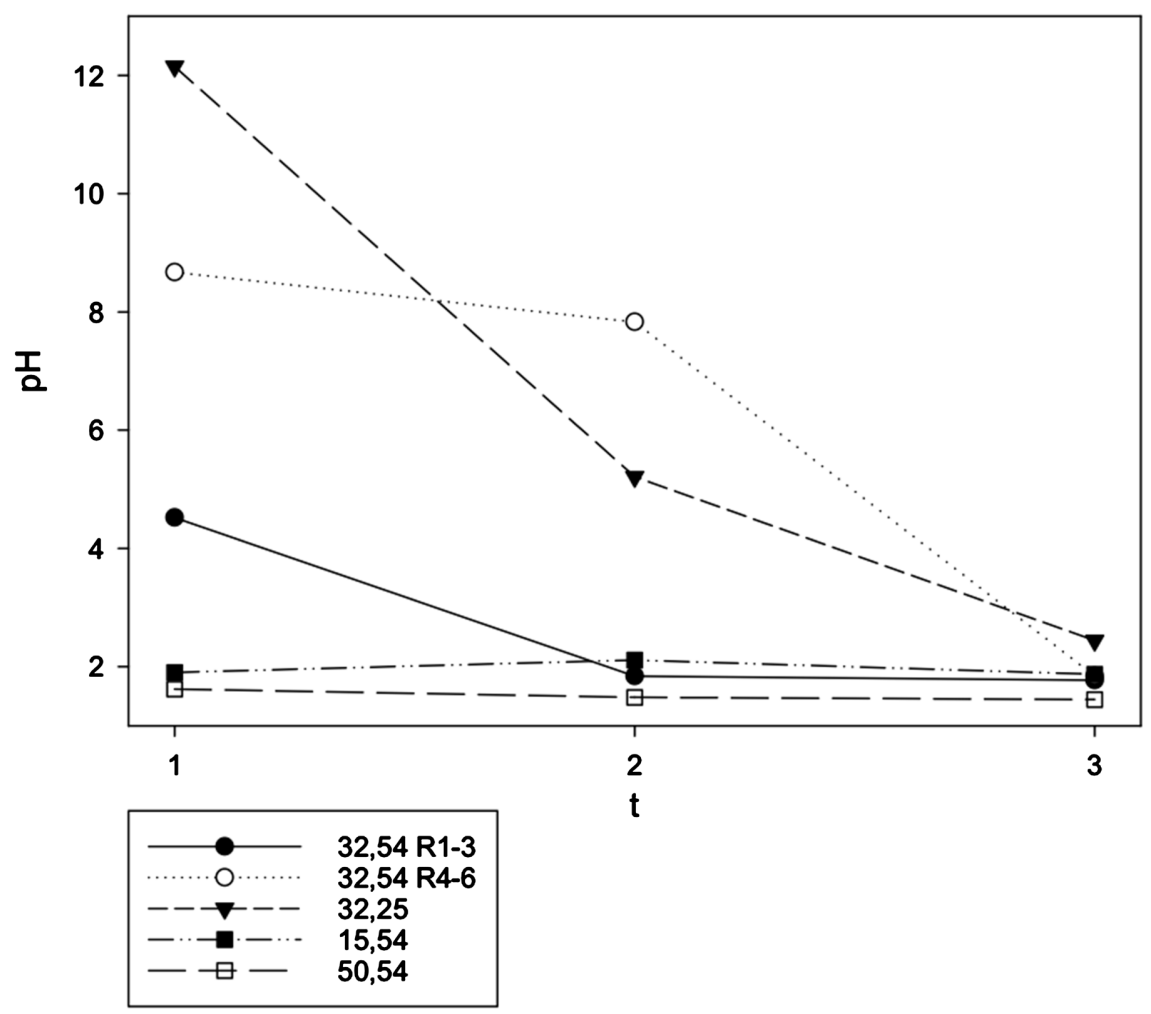

Figure 5. Tank B102L: average $\mathrm{pH}$ values of the samples taken from tank B102L throughout each run for each variation. $T$ is the time of the draw. 1 is when water reached the weir in tank B102; 2 is 2 minutes after the first draw; 3 is after the 2 minutes settling period after the system ran for 10 minutes. In graph legend, the number of milliliters of $\mathrm{NaOH}$ is first, followed by $\mathrm{FeCl}_{3}$.
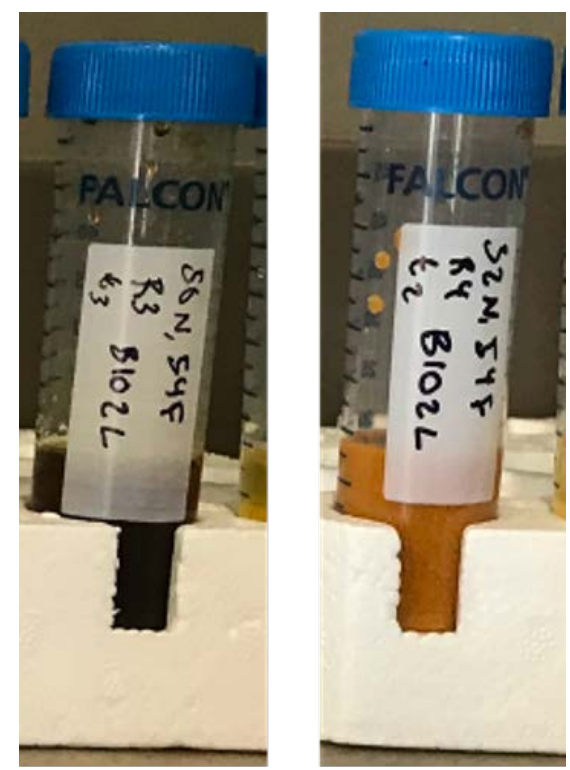

Figure 6. On the left is a picture of an example of the samples for tank B102L that came out as a transparent, brown liquid. On the right is an example of the samples from tank B102L that came out as an opaque floc (samples in picture are shaken). When not shaken, the brown liquid remains the same, while the opaque floc settles into a layer on the bottom with clear liquid on top. 
$\mathrm{NaOH}, 54 \mathrm{~mL} \mathrm{FeCl}_{3}$ and $50 \mathrm{~mL} \mathrm{NaOH}, 54 \mathrm{~mL} \mathrm{FeCl}_{3}$ stayed fairly level throughout all three samples.

Tank B201 had pHs in a range of 12 to 12.5 (Figure 7). This finished water was clear with a hint of yellow and showed the same results as the water in tank $\mathrm{B} 102 \mathrm{U}$. The water in tank B102U was a similar color. This water ran over the edge of a weir and was transported to tank B201. The similarity in $\mathrm{pH}$ was the result that we expected. Variation from the highest $\mathrm{pH}$ to lowest $\mathrm{pH}$ occurred as follows:

$15 \mathrm{~mL} \mathrm{NaOH}, 54 \mathrm{~mL} \mathrm{FeCl}_{3}$

$32 \mathrm{~mL} \mathrm{NaOH}, 54 \mathrm{~mL} \mathrm{FeCl}_{3}$, runs 4 - 6

$32 \mathrm{~mL} \mathrm{NaOH}, 25 \mathrm{~mL} \mathrm{FeCl}_{3}$

$32 \mathrm{~mL} \mathrm{NaOH}, 54 \mathrm{~mL} \mathrm{FeCl}_{3}$, runs 1 - 3

$50 \mathrm{~mL} \mathrm{NaOH}, 54 \mathrm{~mL} \mathrm{FeCl}_{3}$

\subsection{Conductance}

All chemistry variations had consistent conductance within their group in the tank B102U location (Figure 8). In comparison, the samples with different chemistry had large variation in conductance. The $15 \mathrm{~mL} \mathrm{NaOH}, 54 \mathrm{~mL} \mathrm{FeCl}_{3}$ mixture had a conductance of 17 millimho while the $50 \mathrm{~mL} \mathrm{NaOH}, 54 \mathrm{~mL} \mathrm{FeCl}{ }_{3}$ preparation tested at 50 millimho. The order of conductance from the highest to the lowest was:

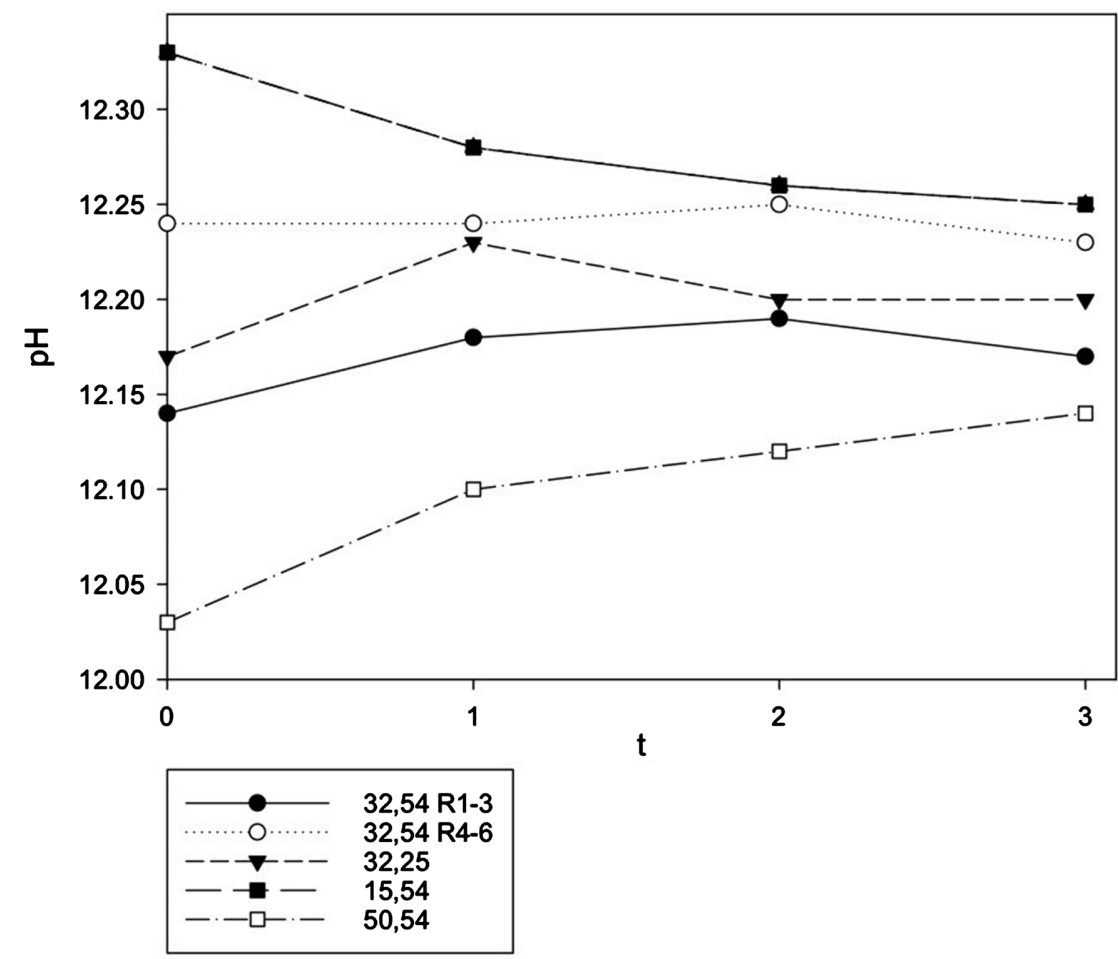

Figure 7. Tank B201: average $\mathrm{pH}$ values of the samples taken from tank B201 throughout each run for each variation. $\mathrm{T}$ is the time of the draw. 0 is of the "raw water" $(\mathrm{NaOH}$ and water) before the run began; 1 is when water reached the weir in $\operatorname{tank} \mathrm{B} 102 ; 2$ is 2 minutes after the first draw; $\mathbf{3}$ is after the 2 minutes settling period after the system ran for 10 minutes. In graph legend, the number of milliliters of $\mathrm{NaOH}$ is first, followed by $\mathrm{FeCl}_{3}$. 


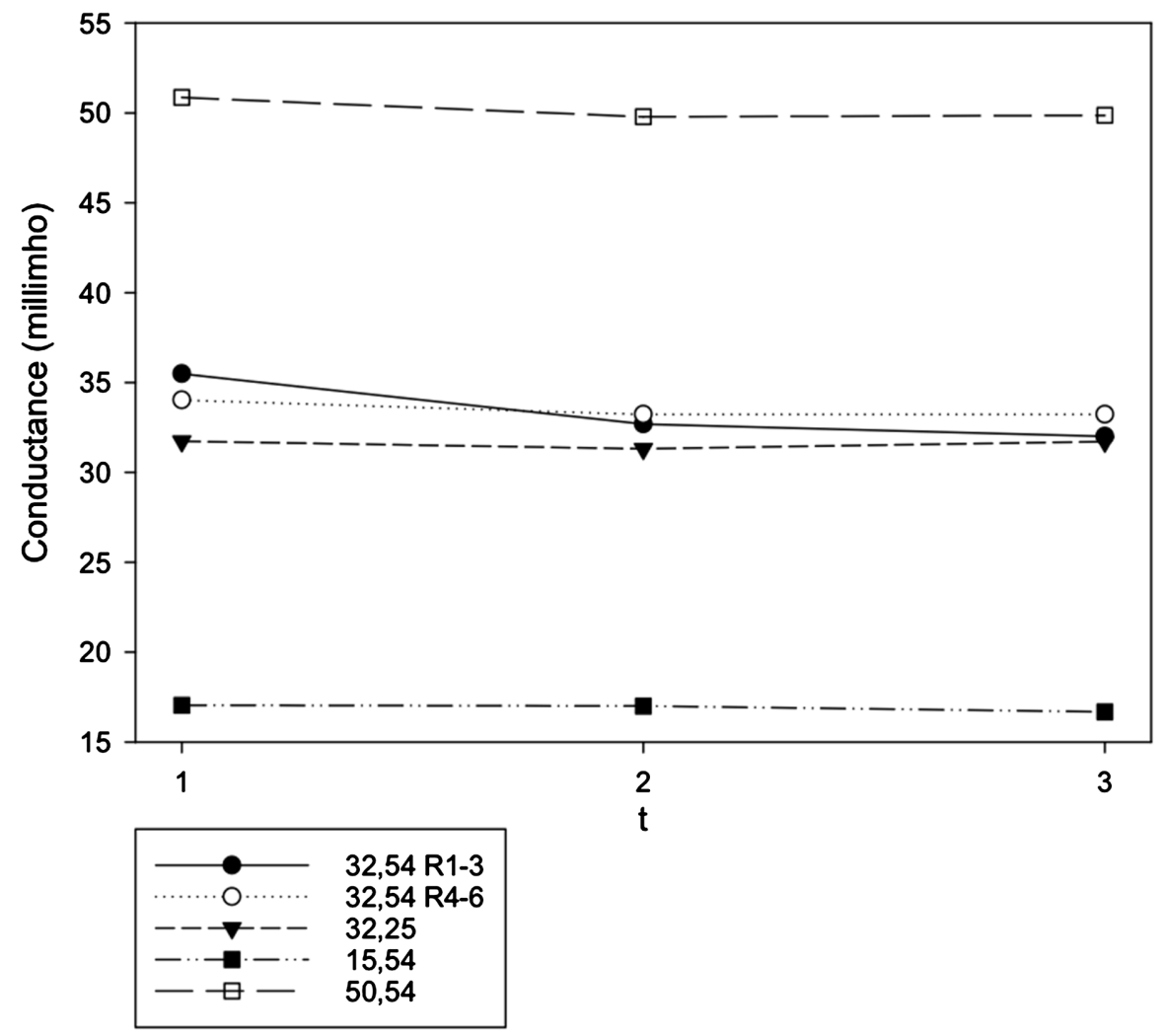

Figure 8. Tank B102U: average conductance values of the samples taken from tank $\mathrm{B} 102 \mathrm{U}$ throughout each run for each variation. $\mathrm{T}$ is the time of the draw. 1 is when water reached the weir in tank B102; 2 is 2 minutes after the first draw; 3 is after the 2 minutes settling period after the system ran for 10 minutes. In graph legend, the number of milliliters of $\mathrm{NaOH}$ is first, followed by $\mathrm{FeCl}_{3}$.

$50 \mathrm{~mL} \mathrm{NaOH}, 54 \mathrm{~mL} \mathrm{FeCl}_{3}$ at 50 millimho

$32 \mathrm{~mL} \mathrm{NaOH}, 54 \mathrm{~mL} \mathrm{FeCl}_{3}$ and $32 \mathrm{~mL} \mathrm{NaOH}, 25 \mathrm{~mL} \mathrm{FeCl}_{3}$ at 35 millimho

$15 \mathrm{~mL} \mathrm{NaOH}, 54 \mathrm{~mL} \mathrm{FeCl}_{3}$ at 17 millimho

Tank B102L had variations in conductance from 15 millimho to 33 millimho (Figure 9). Chemistry mixture $50 \mathrm{~mL} \mathrm{NaOH}, 54 \mathrm{~mL} \mathrm{FeCl}_{3}$ had the highest conductance while the other chemistry groups varied within their sample groups from a low for $32 \mathrm{~mL} \mathrm{NaOH}, 25 \mathrm{~mL} \mathrm{FeCl}_{3}$ and $15 \mathrm{~mL} \mathrm{NaOH}, 54 \mathrm{~mL} \mathrm{FeCl}_{3}$ chemistries and midrange readings for $32 \mathrm{~mL} \mathrm{NaOH}, 54 \mathrm{~mL} \mathrm{FeCl}_{3}$ runs 1 - 3 and 4 - 6 .

Tank B201 averages were the same as those from tanks B102U (Figure 10). This was expected because this water was transported from the B102U location over the weir. Just like in tank B102U, the order of conductance from the highest to the lowest was:

$50 \mathrm{~mL} \mathrm{NaOH}, 54 \mathrm{~mL} \mathrm{FeCl}_{3}$ at 50 millimho

$32 \mathrm{~mL} \mathrm{NaOH}, 54 \mathrm{~mL} \mathrm{FeCl}_{3}$ and $32 \mathrm{~mL} \mathrm{NaOH}, 25 \mathrm{~mL} \mathrm{FeCl}_{3}$ at 35 millimho

$15 \mathrm{~mL} \mathrm{NaOH}, 54 \mathrm{~mL} \mathrm{FeCl}_{3}$ at 17 millimho

\section{3. $\mathrm{pH}$ and Conductance Generalizations}

After measuring the $\mathrm{pH}$ values for all the samples and finding the averages, we 


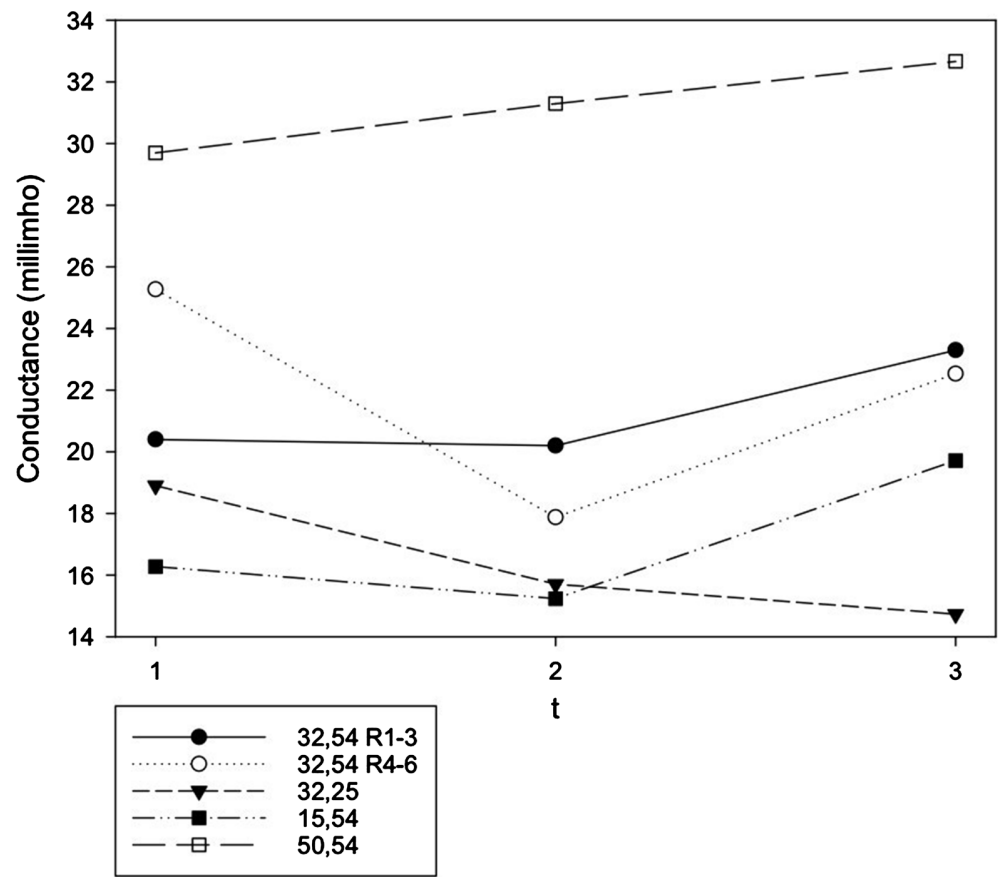

Figure 9. Tank B102L: average conductance values of the samples taken from tank B102L throughout each run for each variation. $t$ is the time of the draw. 1 is when water reached the weir in tank B102; 2 is 2 minutes after the first draw; 3 is after the 2 minutes settling period after the system ran for $10 \mathrm{mi}$ nutes. In graph legend, the number of milliliters of $\mathrm{NaOH}$ is first, followed by $\mathrm{FeCl}_{3}$.

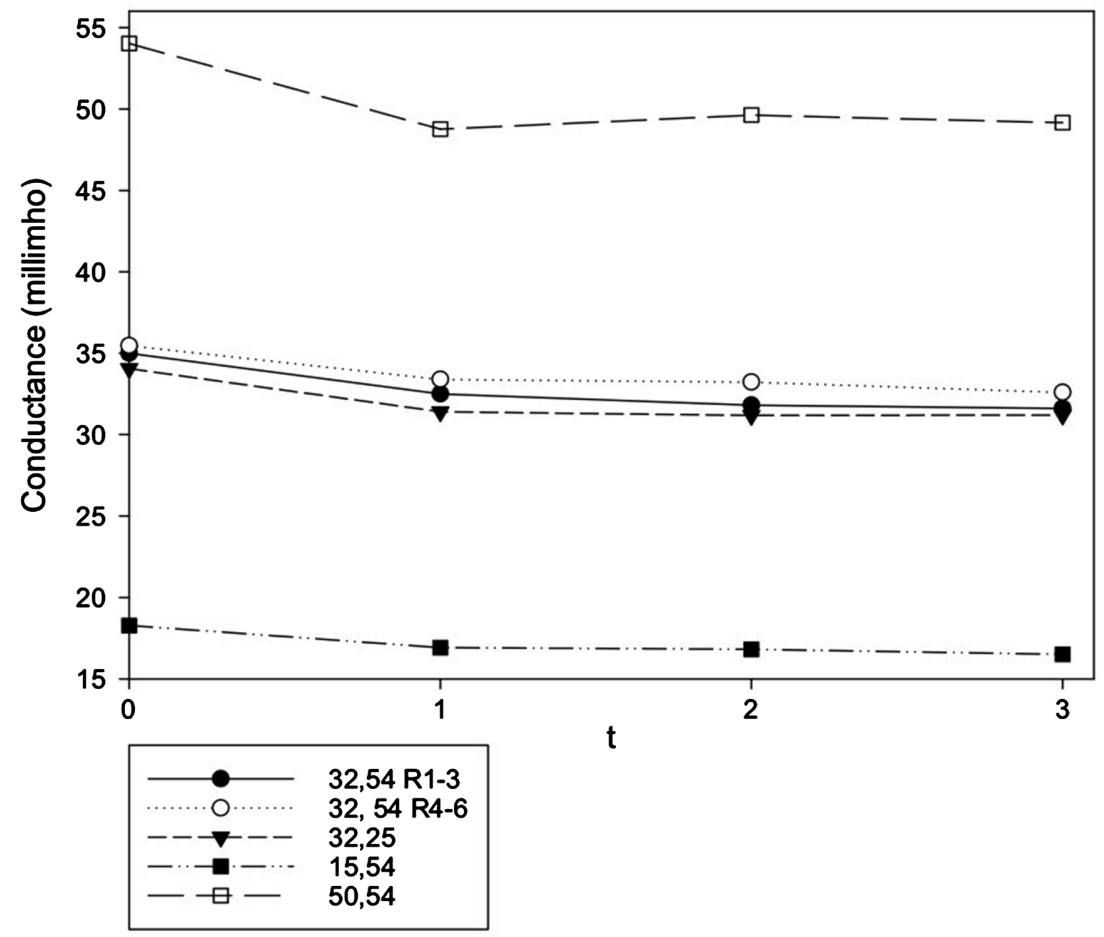

Figure 10. Tank B201: average conductance values of the samples taken from tank B201 throughout each run for each variation. $t$ is the time of the draw. 0 is of the "raw water" $(\mathrm{NaOH}$ and water) before the run began; 1 is when water reached the weir in tank B102; 2 is 2 minutes after the first draw; 3 is after the 2 minutes settling period after the system ran for 10 minutes. In graph legend, the number of milliliters of $\mathrm{NaOH}$ is first, followed by $\mathrm{FeCl}_{3}$. 
observed that the variation with $15 \mathrm{~mL} \mathrm{NaOH}, 54 \mathrm{~mL} \mathrm{FeCl}_{3}$ results in the highest $\mathrm{pH}$ values (most basic) and the variation with $50 \mathrm{~mL} \mathrm{NaOH}, 54 \mathrm{~mL} \mathrm{FeCl}_{3}$ results in the lowest $\mathrm{pH}$ values (most acidic). The other three variations were in the middle. The exception to this pattern was in tank B102L. These results could help demonstrate to students and trainees how the water that leaves the sedimentation tank (B102L) is different from the floc that settles to the bottom. The $\mathrm{pH}$ of the water overflowing the weir in $\mathrm{B} 102 \mathrm{U}$ and the water that ended up in B201 at the end were all very similar, only ranging from a $\mathrm{pH}$ of about 12 to 12.35 (Figure 4 and Figure 7, respectively). Meanwhile, most of the $\mathrm{pH}$ measurements from B102L were highly acidic (Figure 5).

This pattern was the opposite for conductance. The $15 \mathrm{~mL} \mathrm{NaOH}, 54 \mathrm{~mL} \mathrm{FeCl}_{3}$ had the lowest conductance values while the $50 \mathrm{~mL} \mathrm{NaOH}, 54 \mathrm{~mL} \mathrm{FeCl}_{3}$ variation had the highest values. The conductance pattern even seems to follow in tank B102L. Again, B102U and B201 very similar conductance's (Figure 8 and Figure 10 , respectively) while differing more significantly from B102L (Figure 9).

\subsection{Turbidity}

We also planned to run tests on turbidity, however, the typical turbidity tests are run to understand the clarity of water. The test device available in our lab is only for measuring relatively clear water and we determined it would not produce reasonable and consistent results here because the water solution containing floc was opaque. It may be appropriate to use a different type of meter for this test in the future.

\subsection{Visual Representation}

Not only do the results of the experiment have the potential to enhance understanding the water treatment process, but the hands-on visual representation does, as well. Simply reading about coagulation and flocculation only provides so much understanding. The Festo EDS $^{\circledR}$ for Water Management provides students with an effective representation of the separate parts and processes of this step-in water treatment, despite not having a full multichambered system.

\section{Issues and Future Experiments}

There were several issues that made performing the experiment challenging. Some of the instructions for running the experiments with the Festo EDS $^{\circledR}$ for Water Management were unclear or incorrect. At the beginning of the experiment, the instructions for filling tank B201 did not make sense. The tank holds 3.0 liters, however, the instructions said to add a total of 3.5 liters of water, then add the sodium hydroxide, then fill to the 3.0-liter mark on the tank. The tank is overfilled with water before the sodium hydroxide is even added if the instructions are followed. The instructions for making the "raw water" in the "Prepare Raw Water" section were also confusing because there were instructions on how to prepare the sodium hydroxide $50 \%$. However, the sodium hydroxide that 
comes with the $\mathrm{EDS}^{\circledR}$ kit is already at the proper concentration and does not need to be diluted. What is required is that a $50 \%$ sodium hydroxide solution is added to tank B201 to a particular amount of water, thus diluting it.

There were also some issues that occurred with the system itself that required some problem-solving. The impeller flow meters were not working, so the flow rate could not be adjusted properly. It had to be done manually using valve V103. The backflow valve V104 also failed to operate on several occasions so valve V103 had to be closed once pump P201 was turned off to prevent the water from running in reverse. It was also almost impossible to control the input flow off the ferric chloride into the water system. This input flow is critical to produces a gradual flow rate which later produces flocculation. The instructions say to set the valve to 5 drops per second, but the manual valve would not allow for that adjustment. It either dripped slower or flowed at a steady rate. After some experimentation, opening the valve completely to allow a continuous flow seemed to allow for proper flocculation.

A variety of other experiments could help students better understand coagulation and flocculation. Students could investigate how the flow rate of ferric chloride or that of the raw water affects the mixing floc formation. While these were not part of our official experiment, they were both things that we had to adjust various times while deciding how to set up and run the system for our experiment to allow for proper mixing of the coagulant and "raw water". Playing with these setting could help students understand the importance of flow rate. The time the floc is allowed to settle at the end could also be varied before taking the final sample. In future experiments, another good measurement to take would be the amount of floc that settled. Different coagulants could also be experimented with.

\section{Conclusion}

The shortage of trained incoming employees is well known in academia, startups, utilities, and industries. To have college students succeed in water education and research anything that they can learn in high school or technical college on the topic will insure a better retention rate at their next level. The tools we researched could be used for that purpose as well as general education of the public.

After pursuing methods for hands-on education and automation training hardware and software, some of which are not accessible or complete, we were able to perform this research to evaluate whether the EDS system is appropriate for educational research. After performing experiments on a selected topic, we had a few suggestions for improvement in the training materials, but we considered very successful the technical results and conclusions we could draw out of this experiment. We believe that adding this system and its very thorough instruction package to a curriculum regarding water purification, transportation, and wastewater processing would provide hands on learning and experimenting. 
We experimented on only one element of the system, purification of raw water using sedimentation and flocculation. Many other areas of the system could be used to produce learning opportunities. The idea of experimenting with different chemistries and measurement equipment allowed us to experience a more in-depth knowledge of the science and the system. This could be a very good way to lead students into further studies and ultimately careers in the water industry.

\section{Acknowledgements}

Authors thank Alice Lecus for assistance with preparation of solutions and use of handheld devices. Authors thank Rexnord for allowing our team to utilize the EDS system to perform this research.

\section{Conflicts of Interest}

The authors declare no conflicts of interest regarding the publication of this paper.

\section{References}

American Water Works Association, \& Edzwald, J. (2011). Water Quality \& Treatment: A Handbook on Drinking Water (6th ed.). McGraw-Hill Education. https://www.accessengineeringlibrary.com/content/book/9780071630115

Bratby, J. (2016). Coagulation and Flocculation in Water and Wastewater Treatment (3rd ed., Vol. 15). IWA Publishing. https://doi.org/10.2166/9781780407500 https://ebookcentral-proquest-com.ac.ezproxy.switchinc.org/lib/alverno-ebooks/detail. action? docID $=4732971$

Burkolter, D., Kluge, A., German, S., \& Grauel, B. (2009). Wastewater Treatment Simulation (WaTr Sim): Validation of a New Process Control Simulation Tool for Experimental Training Research. Proceedings of the Human Factors and Ergonomics Society Annual Meeting, 53, 1969-1973. https://doi.org/10.1177/154193120905302619

EON Reality (2015, August 11). EON Reality and Festo Aquatronics Virtual Reality Simulator Debuting at World Skills São Paulo 2015.

https://eonreality.com/eon-reality-and-festo-aquatronics-virtual-reality-simulator-deb uting-at-worldskills-sao-paulo-2015/

EON Reality (n.d.). VR Waste Management Training.

Festo Corporation (n.d.-a). Mixed Reality. https://www.festo.com/us/en/e/technical-education/digital-learning/mixed-reality-id 3 $\underline{1287 /}$

Festo Corporation (n.d.-b). Water Management. https://www.festo.com/us/en/e/technical-education/learning-systems/environmental-a nd-renewable-energy/water-management-id 33012/

Flancher, D. (2019). 2019 State of the Water Industry: A Rising Tide? Journal AWWA, 111, 70-77. https://doi.org/10.1002/awwa.1327

Gralton, D. (2018). Calling All Operators: Water Focus. In Qld Water Directorate Articles (pp. 80-83). Institute of Public Works Engineering Australasia Queensland. http://ipweaq.intersearch.com.au/ipweaqjspui/handle/1/4658

Groß, M., Klippstein, C., Maurer, P., Salazar, Y., Treffry-Goatley, K., Voortman, J., \& 
Wehlers, C. (2013). EDS ${ }^{\circledR}$ Water Management-Water purification: Workbook. Festo Didactic GmbH \& Co. KG.

Kane, J., \& Tomer, A. (2018). Renewing the Water Workforce: Improving Water Infrastructure and Creating a Pipeline to Opportunity. Brookings.

Lapikas, T., Worm, G. I. M., Helm, A. W. C. van der, \& Rietveld, L. C. (2009). Waterspot: A Drinking Water Simulator with Training and Process Optimization Capabilities. In J. Boxall, \& Č. Maksimović (Eds.), Integrating Water Systems: Proceedings of the 10th International Conference on Computing and Control for the Water Industry (pp. 475-479). CRC Press.

Lui, S. M., Lemmon, C., Hamilton, J., \& Joy, A. (2012). Standardised Training Simulations: A Case Study of the Water Industry in Australia. In 6 th European Conference on Games-Based Learning (pp. 294-300). University College Cork and Waterford Institute of Technology. https://researchonline.jcu.edu.au/23265/

Mirauda, D., Capece, N., \& Erra, U. (2019). StreamflowVL: A Virtual Fieldwork Laboratory that Supports Traditional Hydraulics Engineering Learning. Applied Sciences, 9, Article No. 4972. https://doi.org/10.3390/app9224972

Mirauda, D., Capece, N., \& Erra, U. (2020). Sustainable Water Management: Virtual Reality Training for Open-Channel Flow Monitoring. Sustainability, 12, Article No. 757. https://doi.org/10.3390/su12030757

MMSD (n.d.). MMSD Central Laboratory. https://www.mmsd.com/what-we-do/water-quality/mmsd-central-lab

Nedeljkovic, M. S., Cantrak, D., Jankovic, N., Ilic, D., \& Matijevic, M. (2019). Virtual Instrumentation Used in Engineering Education Set-Up of Hydraulic Pump and System. In M. E. Auer, \& R. Langmann (Eds.), Smart Industry \& Smart Education (pp. 686-693). Springer International Publishing. https://doi.org/10.1007/978-3-319-95678-7 75

Prakash, N. B., Sockan, V., \& Jayakaran, P. (2014). Waste Water Treatment by Coagulation and Flocculation. International Journal of Engineering Science and Innovative Technology, 3, 479-484.

https://www.researchgate.net/profile/Prakash_Nanjan_Bellie/publication/273638362

Waste Water Treatment by Coagulation and Flocculation/links/556eb5ec08aec2268 $\underline{308 \mathrm{cbbc} / \text { Waste-Water-Treatment-by-Coagulation-and-Flocculation.pdf }}$

Samrani, A. G. El, Lartiges, B. S., Montarg, E., Es-Pelletier, Kazpard, V., Barr, O., \& Ghanbaja, J. (2004). Clarification of Municipal Sewage with Ferric Chloride: The Nature of Coagulant Species. Water Research, 38, 756-768.

https://doi.org/10.1016/j.watres.2003.10.002

Shammas, N. K. (2005). Coagulation and Flocculation. In Lawrence K. Wang, Y. T. Hung, \& N. K. Shammas (Eds.), Physicochemical Treatment Processes (Vol. 3, pp. 103-139). Humana Press. https://doi.org/10.1385/1-59259-820-x:103

United States Government Accountability Office (2018). Water and Wastewater Workforce: Recruiting Approaches Helped Industry Hire Operators, but Additional EPA Guidance Could Help Identify Future Needs. https://www.gao.gov/assets/690/689621.pdf

Van Der Helm, A. W. C., Oonincx, M., Lapikas, T., Van Schagen, K. M., \& Rietveld, L. C. (2012). A Drinking Water Treatment Plant Simulator Using Real-Time Plant Data for Enhanced Operator Training and Model Evaluation. Water Supply, 12, 241-249. https://doi.org/10.2166/ws.2012.132

Van der Wees, M. (2009). Using a Drinking Water Treatment Simulator for Operator Training: Accelerating the Simulated Process Leads to an Increase in Learning. Delft 
University of Technology.

https://repository.tudelft.nl/islandora/object/uuid\%3Acdc194ff-394b-4772-a0ed-feada1 dd7a06

Worm, G. I. M., Van Der Wees, M., De Winter, J. C. F., De Graaf, L., Wieringa, P. A., \& Rietveld, L. C. (2012). Training and Assessment with a Faster than Real-Time Simulation of a Drinking Water Treatment Plant. Simulation Modelling Practice and Theory, 21, 52-54. https://doi.org/10.1016/j.simpat.2011.09.007 